\title{
(2) OPEN ACCESS \\ Neuraxial and peripheral misconnection events leading to wrong-route medication errors: a comprehensive literature review
}

\author{
Eugene R Viscusi 다, ${ }^{1}$ Vincent Hugo, ${ }^{2}$ Klaus Hoerauf, ${ }^{2,3}$ Frederick S Southwick ${ }^{4}$
}

${ }^{1}$ Department of Anesthesiology, Thomas Jefferson University, Philadelphia, Pennsylvania, USA ${ }^{2}$ Becton, Dickinson and Company, Franklin Lakes, New Jersey, USA

${ }^{3}$ Department of Anesthesiology and Intensive Care Medicine, Medical University of Vienna, Wien, Austria

${ }^{4}$ Department of Medicine, University of Florida, Gainesville, Florida, USA

\section{Correspondence to} Dr Eugene R Viscusi, Thomas Jefferson University, Philadelphia, Pennsylvania, USA; eugene.viscusi@jefferson.edu

Received 19 June 2020 Revised 24 September 2020 Accepted 29 September 2020

Published Online First

3 November 2020

\section{ABSTRACT}

We conducted a search of the literature to identify case reports of neuraxial and peripheral nervous system misconnection events leading to wrong-route medication errors. This narrative review covers a 20-year period (1999-2019; English-language publications and abstracts) and included the published medical literature (PubMed and Embase) and public access documents. Seventy-two documents representing 133 case studies and 42 unique drugs were determined relevant. The most commonly reported event involved administering an epidural medication by an intravenous line (29.2\% of events); a similar proportion of events (27.7\%) involved administering an intravenous medication by an epidural line. Medication intended for intravenous administration, but delivered intrathecally, accounted for $25.4 \%$ of events. In the most serious cases, outcomes were directly related to the toxicity of the drug that was unintentionally administered. Patient deaths were reported due to the erroneous administration of chemotherapies $(n=16)$, muscle relaxants $(n=4)$, local anesthetics $(n=4)$, opioids $(n=1)$, and antifibrinolytics $(n=1)$. Severe outcomes, including paraplegia, paraparesis, spinal cord injury, and seizures were reported with the following medications: vincristine, gadolinium, diatrizoate meglumine, doxorubicin, mercurochrome, paracetamol, and potassium chloride. These case reports confirm that misconnection events leading to wrong-route errors can occur and may cause serious injury. This comprehensive characterization of events was conducted to better inform clinicians and policymakers, and to describe an emergent strategy designed to mitigate patient risk.

\section{INTRODUCTION}

Neuraxial and peripheral analgesia are being used in a growing number of indications. ${ }^{12}$ Neuraxial anesthesia commonly supplements general anesthesia, and may serve as the primary anesthetic for surgeries conducted in the mediastinal region and lower extremities. It is applied in intraoperative, postoperative, and peripartum settings, as well as in end-of-life care. Increasingly, neuraxial routes are being used for acute pain therapy, chronic pain management, and diagnostic procedures. Peripheral nerve blocks provide pain control for patients undergoing surgery, and avoid the need for, and adverse effects linked to, opioids and volatile anesthetics. ${ }^{12}$ Given the range of neuraxial and peripheral applications, opportunities for human error are present.
Misconnection events can occur when delivery systems, such as tubes, syringes, or other accessories, are erroneously connected via an unintended route (eg, enteral, intravascular, neuraxial, or respiratory), leading to wrong-route medication administration. $^{3-5}$ An example would be intravenous medication delivered to the epidural space. ${ }^{4}$ Misconnections leading to wrong-route medication delivery have been reported across a number of medical specialties, including anesthesiology, emergency medicine, obstetrics, and oncology. ${ }^{6-9}$ These events have occurred in a variety of settings, including inpatient surgery, ${ }^{10-14}$ labor and delivery, ${ }^{615}$ and intensive care units. ${ }^{16} 17$

Because of a lack of organized and publicly available reporting, it is not possible to assess the rate of misconnections wherein the denominator is the total number of catheter-based neuraxial and peripheral procedures. ${ }^{4} 18-21$ Several published reviews document that tubing misconnections are uncommon $^{22-24}$; however, national research and hospital-based analyses confirm that misconnection events occur. For example, between January 2000 and December 2004, reports of more than 300 errors involving inappropriate intravenous/ intravascular medication administration errors due to tubing interconnectivity were submitted to the US MEDMARX medication error-reporting database. $^{22}$ Misconnections have also been reported by the Australian drug error database, ${ }^{24}$ a hospital in Japan, ${ }^{25}$ and tertiary care hospitals in South Africa. ${ }^{26}$

When these errors do occur, they exert a high burden in terms of morbidity and mortality, patient suffering, and expenses. ${ }^{27-29}$ In 2006, the Institute of Medicine estimated the average cost of managing any type of serious medication error to be US\$8750 per preventable adverse drug event. ${ }^{30}$ These expenses can also include litigation costs and fines to hospitals, as well as increased length of stay and hospitalization costs. ${ }^{19} 31-33$

The goal of this narrative review is to characterize the current understanding of neuraxial and peripheral nervous system misconnection errors, and to motivate clinicians and health systems to consistently adopt the new International Organization for Standardization's (ISO) standards.

\section{METHODS}

This narrative review is based on a search of the medical literature and public access documents (English-language publications or abstracts) published between January 1, 1999, and September 
30, 2019. Searches were conducted on PubMed and Embase using a Boolean strategy that initially applied US National Library of Medicine Medical Subject Headings (MeSH) terms to identify human cases; subsequently, a comprehensive sequence of $\mathrm{MeSH}$ and free-text terms were used to search indexed and non-indexed publications. These terms included: accidental, anaesth"/anesth", 'anesthetic incidents', avoid*, blockade, bore, caudal, connector", confus", deadly, 'drug administration routes', drug error(s), 'drug labeling', 'drug overdose', epidural, erroneous"/error", extradural, faulty, inadvertent infusion, injection, incident monitoring and reporting, interconnect", intrathecal, intravenous, 'Luer/Luer lock', maladminist", medication error(s), misconnect", mistake", mixup/mix-up(s), 'mode of delivery', 'near-miss(es)', 'nerve block', 'non-Luer', 'organisational accidents', peridural, peripheral, preventable, route, spinal, subarachnoid, syringe, 'tube/tubing', uninten", 'universal connector', 'universal design', unknowingly, ventricular, 'wrong ", and 'wrong route'. Similar terms were also applied to a general internet search for public access documents. See online supplemental table 1 for a full summary of literature search terms applied.

The literature search was supplemented by bibliographic review of key source documents to identify case reports specific to wrong-route misconnection. Only case reports and other relevant publications that confirmed a misconnection event and noted the name of the drug administered and the patient's health outcomes were included. Likewise, wrong-route cases attributed to causes other than misconnection (eg, mislabeled medication bags) were not included in the final analysis. Finally, to avoid reporting twice on the same case, source documents were reviewed closely to identify duplicate reports involving the same patient.

Once identified, cases were aggregated and descriptive analyses were conducted. The severity of each event was assessed using the National Reporting and Learning System incident criteria, ${ }^{23}$ as follows: (Low) Any unexpected or unintended incident that required extra observation or minor treatment and caused minimal harm to $\geq 1$ person; (Moderate) Any unexpected or unintended incident that resulted in further treatment, possible surgical intervention, or canceling of treatment or transfer to another area, and which caused short-term harm to $\geq 1$ person; (Severe) Any unexpected or unintended incident that caused permanent or long-term harm to $\geq 1$ person; (Death) Any unexpected or unintended event that caused the death of $\geq 1$ person. In addition, the frequency of reported misconnection/ wrong-route events associated with specific drugs, and the drugs associated with high morbidity and mortality rates when administered by the wrong route, were evaluated.

\section{RESULTS}

Approximately 200 unique publications were identified for fulltext review; of these, 72 documents representing 133 case studies were determined to be relevant, and of these cases, 130 were included in the final case analysis (three were excluded owing to incomplete information regarding precise drug delivery route). Case study sources were published case reports and clinical studies (including journal manuscripts and scientific congress abstracts), as well as national policy alerts that included case study summaries. Case studies were identified from 25 countries and 6 continents (Africa, Asia, Australia/New Zealand, Europe, and North and South America) over a time period spanning from 1999 to 2019.

Of the reviewed documents, the most commonly reported neuraxial misconnection event type involved administration of medications intended for the epidural route by the intravenous route $(29.2 \%, 38 / 130)^{11252634-41}$; a similar proportion of events involved the directionally opposite error (ie, administering medications intended for the intravenous route by the epidural route), at $27.7 \%(36 / 130)^{101424-2641-66}$ (figure 1).

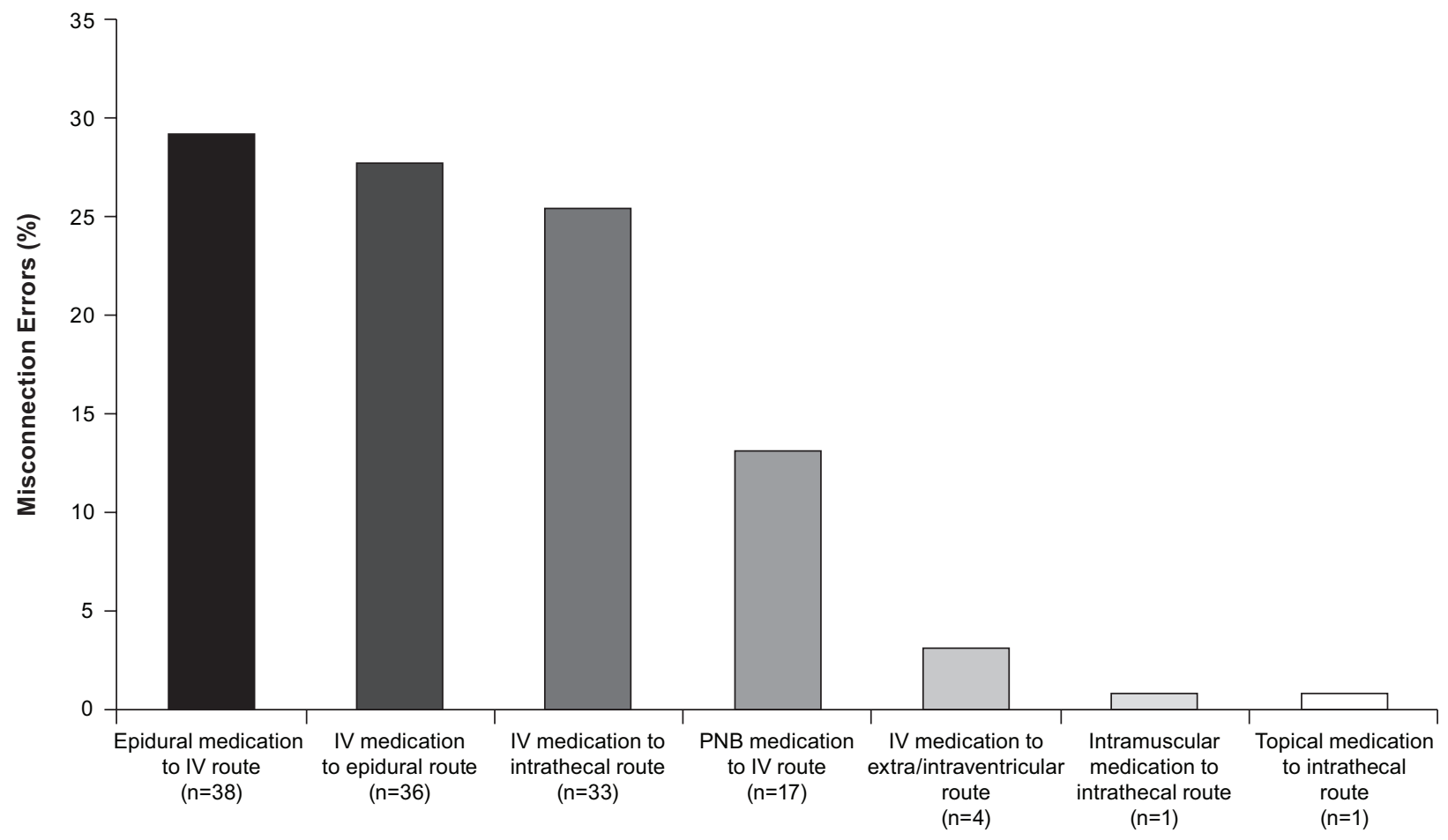

Figure 1 Neuraxial and peripheral nerve block misconnection errors identified in case reports ( $N=130)$ between 1999 and 2019 . Intended route unknown for 3 of 133 cases. IV, intravenous; PNB, peripheral nerve block. 
Table 1 Number, severity, ${ }^{*}$ and route of drug administration errors identified in case reports: drugs with at least two case reports

\begin{tabular}{|c|c|c|c|c|c|c|}
\hline & & & Event seve & cale & & \\
\hline & & & Low & Moderate & Severe & Death \\
\hline Drug name & Drug class & Events (n) & Incident(s) & & & \\
\hline Vincristine†‡ & Chemotherapy & 19 & & & 4 & 15 \\
\hline Potassium chloridet & $\mathrm{N} / \mathrm{A}$ & 6 & & 5 & 1 & \\
\hline Bupivacaine§ & Local anesthetic & 5 & 1 & & & 4 \\
\hline Thiocolchicosidet & Muscle relaxant & 4 & & & & 4 \\
\hline Gadolinium I & Contrast agent & 3 & & 1 & 2 & \\
\hline Ropivacaine§ & Local anesthetic & 3 & 1 & 2 & & \\
\hline Vecuroniumt & Muscle relaxant & 3 & 1 & 2 & & \\
\hline Paracetamolt & Pain reliever & 2 & & 1 & 1 & \\
\hline Tranexamic acid $\neq$ & Antifibrinolytic & 2 & 1 & & & 1 \\
\hline Oxytocint & $\mathrm{N} / \mathrm{A}$ & 2 & & 2 & & \\
\hline Ephedrinet & Nonselective adrenergic agonist & 2 & 2 & & & \\
\hline Succinylcholinet & General anesthetic & 2 & 2 & & & \\
\hline Thiopentalt & General anesthetic & 2 & 2 & & & \\
\hline
\end{tabular}

${ }^{*}$ Incident severity, as defined by the National Reporting and Learning System, ${ }^{23}$ is as follows: (Low) An unexpected or unintended incident that required extra observation or minor treatment and caused minimal harm to $\geq 1$ person; (Moderate) Any unexpected or unintended incident that resulted in further treatment, possible surgical intervention, canceling of treatment, or transfer to another area, and which caused short-term harm to $\geq 1$ person; (Severe) Any unexpected or unintended incident that caused permanent or long-term harm to $\geq 1$ person; (Death) Any unexpected or unintended event that caused the death of $\geq 1$ person.

†Intravenous to epidural.

¥Intravenous to intrathecal.

$\S$ Epidural to intravenous.

IIntravenous to intraventricular/extraventricular.

N/A, not applicable.

Medications intended for intravenous administration have been directly administered by the intrathecal route $(25.4 \%, 33 / 130)$ due to misconnections. ${ }^{1967-92}$ Less frequently, the misconnection error was the unintentional administration of a peripheral nerve block via the intravenous route $(13.1 \%, 17 / 130)$. Two instances each have been described of injecting intravenous drugs into an intraventricular line $e^{13}$ or into an extraventricular drain. ${ }^{16} 93$ Least common were topical or intravascular medications administered by the intrathecal route, with one case each $(0.77 \%) .{ }^{94} 95$ Although not a misconnection error, there have been instances of peripheral nerve block medications being administered on the wrong side of the body $(7.9 \%, 10 / 126) .{ }^{24}$

The literature search identified 42 unique drugs or other substances injected via a misconnection event leading to wrong-route error; these misconnections were primarily neuraxial, but also included peripheral neural administration. Table 1 summarizes the 13 drugs with at least two published cases. Drug classes included: contrast agents, ${ }^{13} 93$ general anesthetics, ${ }^{47576064}$ local anesthetics, ${ }^{11}{ }^{34-38}$ muscle relaxants, ${ }^{46} 5061$ antifibrinolytics, ${ }^{81} 92$ nonselective adrenergic agonists, ${ }^{56}{ }^{59}$ and nonsteroidal anti-inflammatory drugs. ${ }^{44} 45$ The greatest number of patient deaths were due to the erroneous administration of vincristine $(\mathrm{n}=15),{ }^{19} 687375-7880828487-8996$ thiocolchicoside $(n=4),{ }^{41}$ and bupivacaine $(n=4) .{ }^{3738}$ Moderate to severe harm has been caused by the erroneous epidural administration of potassium chloride ${ }^{49} 52-5462$ and oxytocin. ${ }^{4358}$ Detailed descriptions of the sequence of events in two cases of neuraxial misconnections are presented in online supplemental table 2).

For most drugs, or drug combinations, identified, there was only a single reported incident of accidental delivery; these drugs are listed in table 2. ${ }^{6997}$ Among these cases, drugs came primarily from the following classes: antibiotics, ${ }^{10} 427290$ chemotherapy agents, ${ }^{197479} 94$ contrast agents, ${ }^{69838591}$ muscle relaxants other than thiocolchicoside, ${ }^{5163}$ and opioids. ${ }^{425571}$ Patient deaths were reported due to the erroneous intrathecal administration of the chemotherapy agent farmorubicin ${ }^{19}$ and tramadol. ${ }^{71}$ Other drug classes represented include beta blockers, ${ }^{70}$ acetylcholinesterase inhibitors, ${ }^{65}$ anticholinergics, ${ }^{65}$ decongestants, anticonvulsants, ${ }^{16}$ and cholinesterase inhibitors. ${ }^{86}$ Last, cases were reported involving the wrong-route administration of insulin, ${ }^{48}$ mercurochrome, ${ }^{95}$ parenteral nutrition, ${ }^{41}$ and sodium chloride. ${ }^{66}$

\section{DISCUSSION}

This literature search identified published case reports describing neuraxial and peripheral misconnection events leading to wrongroute errors over a 20 -year period. These events occurred across a range of healthcare settings and specialty areas and primarily involved the inadvertent delivery of drugs intended for intravenous administration via the intrathecal ${ }^{19} 67-697173$ 75-80 $828487-89$ or epidural $^{414552}$ routes. Both death ${ }^{1937384168717375-7780828789}$ and serious morbidity (including paraplegia, paraparesis, spinal cord injury, and seizures) ${ }^{4552676978798488}$ were associated with intravenous and neuraxial line misconnection errors. For most drugs identified, there was only a single reported incident of accidental delivery; this finding is similar to the results of previous literature reviews. ${ }^{69997}$ In the most serious cases, outcomes were directly related to the toxicity of the drug that was inadvertently administered (eg, vincristine).

The case studies discussed in this narrative review support findings from several national monitoring systems that have evaluated the frequency of wrong-route misconnection errors. This research has consistently shown that these events occur, and that outcomes can be severe. ${ }^{22-242798}$ For example, data from the US MEDMARX national error-reporting program and the Australian Incident Monitoring Study database suggest that between 1 in 25 and 1 in 250 intravenous-related medication errors are due to misconnections. ${ }^{22} 24$ Likewise, a retrospective analysis of the French Pharmacovigilance System found that 27 (96\%)/28 cases of neuraxial wrong-route errors resulted in a serious adverse 
Table 2 Individual drugs and other substances noted in a single case report involving neuraxial and peripheral misconnections, leading to wrongroute administration events

\begin{tabular}{|c|c|c|c|}
\hline Drug type, name & Intended route of administration & Actual route of administration & Incident severity* \\
\hline \multicolumn{4}{|l|}{ Antibiotics } \\
\hline Cefotiam & Intravenous & IT & Moderate \\
\hline Clindamycin & Intravenous & EPI & Low \\
\hline Piperacillin-tazobactam & Intravenous & EPI & Moderate \\
\hline Rifampicin & Intravenous & IT & Low \\
\hline \multicolumn{4}{|l|}{ Chemotherapy } \\
\hline Bleomycin & Intravenous & IT & Moderate \\
\hline Doxorubicin & Intravenous & IT & Severe \\
\hline Farmorubicin & Intravenous & IT & Death \\
\hline PEG-asparaginase & Intramuscular & IT & Low \\
\hline \multicolumn{4}{|l|}{ Contrast agents } \\
\hline Diatrizoate meglumine & Intravenous & IT & Moderate \\
\hline lothalamate meglumine & Intravenous & IT & Moderate \\
\hline loxaglate sodium & Intravenous & IT & Moderate \\
\hline loxitalamate & Intravenous & IT & Moderate \\
\hline \multicolumn{4}{|l|}{ Muscle relaxants } \\
\hline Cisatracurium & Intravenous & $\mathrm{EPI}$ & Moderate \\
\hline Pancuronium & Intravenous & EPI & Low \\
\hline \multicolumn{4}{|l|}{ Opioids } \\
\hline Hydromorphone & Intravenous & EPI & Moderate \\
\hline Remifentanil & Intravenous & EPI & Low \\
\hline Tramadol & Intravenous & IT & Death \\
\hline \multicolumn{4}{|l|}{ Other } \\
\hline Insulin & Intravenous & EPI & Moderate \\
\hline Labetalol-beta blocker & Intravenous & IT & Low \\
\hline Mercurochrome & TOP & IT & Severe \\
\hline Neostigmine + atropine & Intravenous & $\mathrm{EPI}$ & Moderate \\
\hline Parenteral nutrition & Intravenous & EPI & Moderate \\
\hline Phenylephrine & Intravenous & $\mathrm{EPI}$ & Moderate \\
\hline Phenytoin & Intravenous & ED & Moderate \\
\hline Physostigmine (cholinesterase inhibitor) & Intravenous & IT & Low \\
\hline Sodium chloride, ketorolac, esomeprazole, cefotaxime & Intravenous & EPI & Low \\
\hline
\end{tabular}

*Incident severity, as defined by the National Reporting and Learning System, ${ }^{23}$ is as follows: (Low) Any unexpected or unintended incident that required extra observation or minor treatment and caused minimal harm to $\geq 1$ person; (Moderate) Any unexpected or unintended incident that resulted in further treatment, possible surgical intervention, or canceling of treatment, or transfer to another area, and which caused short-term harm to $\geq 1$ person; (Severe) Any unexpected or unintended incident that caused permanent or long-term harm to $\geq 1$ person; (Death) Any unexpected or unintended event that caused the death of $\geq 1$ person.

ED, extraventricular drain; EPI, epidural; IT, intrathecal; PEG, polyethylene glycosylated; TOP, topical.

event, and $11(39 \%) / 28$ resulted in patient death. ${ }^{27}$ However, these analyses relied primarily on self-reported information, ${ }^{2224}$ making it impossible to calculate the true incidence of harmful outcomes. During the conduct of this literature review, we observed that the difficulties inherent in collecting error data, including errors that are not noticed or do not result in patient harm, add to the challenge of calculating true incidence. Of note, we observed that research attempting to identify all events using anonymized prospective reporting or observers documented higher rates of error and near-miss events ${ }^{26} 3999$ than research that examined only voluntarily reported events. ${ }^{22-24}$

Universal Luer systems have long been used to securely connect fittings between needles, syringes, and tubing. These connectors serve multiple medication delivery routes, including intravenous, enteral, neuraxial, and respiratory. ${ }^{428} 29$ An unintended consequence of Luer standardization is an increased potential for patient harm or death due to misconnection between administration routes, leading to wrong-route medication administration. ${ }^{428} 29$ Reports of misconnection errors have led to efforts to create new, less error-prone systems. In 2010, the ISO 80369 series provided new standards to replace the universal use of Luer connectors. ${ }^{100}$ The ISO 80369 connectors introduce incompatibility between tubing connections serving different body systems and build in a safeguard to eliminate specific types of error. The ISO 80369-6 standard, introduced in 2016, specifies requirements for new Luer-incompatible neuraxial connectors; Luer connectors will continue to be used only for intravenous connections. Neuraxial applications include the administration of medications to neuraxial sites (ie, the spine, intrathecal space, ventricles of the brain, and the epidural, extradural, or peridural spaces), wound infiltration anesthesia delivery, other regional anesthesia procedures, and monitoring or removing cerebrospinal fluid for therapeutic or diagnostic purposes. ${ }^{101}$

Drug administration is the final step in a complex chain of events that includes procurement, storage, and deployment. ${ }^{102}$ In the hospital setting, there are several time points where medication error may occur, leading to a patient not receiving the right drug at the right time and the right place. ${ }^{22}$ Recognizing the relationship between Luer interconnectivity and medication 
error and adopting new ISO 80369 standards are critical steps in preventing future adverse outcomes.

\section{Limitations}

The data reported here are expected to be incomplete and are not intended to provide an estimate of incidence. This is because chronic under-reporting of misconnection events is widely acknowledged, ${ }^{48-2096103}$ and this literature search was confined to English-language cases. Furthermore, any interpretation of these data must be assessed in context with the relatively low real-world frequency of misconnection complications. When considering the very large number of regional anesthetic procedures performed worldwide, any potential safety intervention would require the treatment of large patient numbers before benefits could be documented. Therefore, it should be acknowledged that it may never be possible to track the true incidence of these events, or the global impact of any specific technologic intervention.

\section{CONCLUSION}

This literature review shows that misconnection events occur and can lead to wrong-route errors, with serious consequences. New technological advances are available that may improve patient safety by preventing misconnection events.

Acknowledgements Assistance with manuscript preparation was provided to the authors by Caitlin Rothermel, MA, MPH of Peloton Advantage, LLC, an OPEN Health company, Parsippany, NJ, USA, and was sponsored by Becton, Dickinson and Company, Franklin Lakes, NJ, USA.

Contributors All authors participated in the planning, preparation, and critical review of this manuscript and granted final approval for submission.

Funding This study was funded by Becton, Dickinson and Company.

Competing interests FSS declares no conflicts of interest. VH and $\mathrm{KH}$ are employees of Becton, Dickinson and Company and own stock or stock options in the company. ERV receives consulting fees from AcelRx, Concentric, Heron Therapeutics, Innacoll, Merck, Neumentum, Pfizer, Recro, Salix, and Trevena.

Patient consent for publication Not required.

Provenance and peer review Not commissioned; externally peer reviewed.

Data availability statement Data sharing not applicable as no datasets generated and/or analyzed for this study.

Open access This is an open access article distributed in accordance with the Creative Commons Attribution Non Commercial (CC BY-NC 4.0) license, which permits others to distribute, remix, adapt, build upon this work non-commercially, and license their derivative works on different terms, provided the original work is properly cited, an indication of whether changes were made, and the use is noncommercial. See: http://creativecommons.org/licenses/by-nc/4.0/.

ORCID iD

Eugene R Viscusi http://orcid.org/0000-0003-0260-4396

\section{REFERENCES}

1 Choi J, Gadsden J. Local anesthetic mixtures for peripheral nerve blocks. In: Hadzic A, ed. Hadzic's Textbook of Regional Anesthesia and Acute Pain Management. 2nd edn. New York: McGraw-Hill Education, 2017

2 Toledano RD, Van de Velde M. Epidural anesthesia and analgesia. In: Hadzic A, ed. Hadzic's Textbook of Regional Anesthesia and Acute Pain Management. 2nd edn. New York: McGraw-Hill Education, 2017.

3 US Food and Drug Administration. Reducing risks through standards development for medical device connectors. Silver Spring, MD. Available: https://www.fda.gov/ medical-devices/medical-device-connectors/reducing-risks-through-standardsdevelopment-medical-device-connectors [Accessed September 22, 2020].

4 Litman RS, Smith VI, Mainland P. New solutions to reduce wrong route medication errors. Pediatr Anaesth 2018;28:8-12.

5 US Food and Drug Administration.. Medical device connectors. Available: https:// www.fda.gov/medical-devices/general-hospital-devices-and-supplies/medicaldevice-connectors [Accessed September 22, 2020].

6 Patel S, Loveridge R. Obstetric neuraxial drug administration errors: a quantitative and qualitative analytical review. Anesth Analg 2015;121:1570-7.
7 Paparella SF, Wollitz A. Mix-ups and misconnections: avoiding intravenous line errors. J Emerg Nurs 2014;40:382-4

8 Beckers A, Verelst $P$, van Zundert A. Inadvertent epidural injection of drugs for intravenous use: a review.. Acta Anaesthesiol Belg 2012;63:75-9.

9 Scalzone M, Coccia P, Cerchiara G, et al. Errors involving patients receiving intrathecal chemotherapy. J Chemother 2010;22:83-7.

10 Agarwal A, Goyal S, Verma AK, et al. Inadvertent injection of piperacillin-tazobactum into epidural space. J Anaesthesio/ Clin Pharmacol 2010:26:559-60.

11 Karaca S, Ünlüsoy EÖ. Accidental injection of intravenous bupivacaine. Eur $J$ Anaesthesiol 2002;19:616-7.

12 Koczmara C, Hyland S, Cheng R. Epidural medications given intravenously may result in death. Dynamics 2007;18:34-6.

13 Nayak NB, Huang JC, Hathout GM, et al. Complex imaging features of accidental cerebral intraventricular gadolinium administration. J Neurosurg 2013;118:1130-4.

14 Townley KR, Lane J, Packer R, et al. Unintentional infusion of phenylephrine into the epidural space. A A Case Rep 2016;6:124-6.

15 Goodman EJ, Haas AJ, Kantor GS. Inadvertent administration of magnesium sulfate through the epidural catheter: report and analysis of a drug error. Int J Obstet Anesth 2006;15:63-7.

16 McConnell P, Macneil C. Accidental intraventricular administration of phenytoin through an external ventricular drain: case report. Am J Crit Care 2011;20:347:343-5

17 Morrison J, Wenstone R, Cloherty L, et al. Drug-related critical incidents in a multidisciplinary intensive care unit [abstract 0127]. Intensive Care Med 2014;40:\$39.

18 Joint Commission. Managing risk during transition to new ISO tubing connector standards. Sentinel Event Alert 2014;53:1-6.

19 Madea B, Musshoff F, Preuss J. Medical negligence in drug associated deaths. Forensic Sci Int 2009;190:67-73.

20 Simmons D, Symes L, Guenter P, et al. Tubing misconnections: normalization of deviance. Nutr Clin Pract 2011;26:286-93.

21 Webster CS, Merry AF, Larsson L, et al. The frequency and nature of drug administration error during anaesthesia. Anaesth Intensive Care 2001;29:494-500.

22 Hicks RW, Becker SC. An overview of intravenous-related medication administration errors as reported to MEDMARX®, a national medication error-reporting program. $J$ Infus Nurs 2006;29:20-7.

23 MacLennan Al, Smith AF. An analysis of critical incidents relevant to pediatric anesthesia reported to the UK National Reporting and Learning System, 2006-2008. Paediatr Anaesth 2011:21:841-7.

24 Abeysekera A, Bergman IJ, Kluger MT, et al. Drug error in anaesthetic practice: a review of 896 reports from the Australian Incident Monitoring Study database. Anaesthesia 2005:60:220-7.

25 Yamamoto M, Ishikawa S, Makita K. Medication errors in anesthesia: an 8-year retrospective analysis at an urban university hospital. J Anesth 2008;22:248-52.

26 Llewellyn RL, Gordon PC, Wheatcroft D, et al. Drug administration errors: a prospective survey from three South African teaching hospitals. Anaesth Intensive Care 2009;37:93-8.

27 Martin-Brisac N, Grene-Lerouge N, Cardona F, et al. Management of medication errors associated with the intrathecal administration instead of intravenous administration at the French agency (ANSM) [abstract ISP3501-37]. Drug Saf 2013;36:823.

28 Cook TM. Non-Luer connectors: are we nearly there yet? Anaesthesia 2012;67:784-92

29 Block M, Horn RJ, Schlesinger MD. Reducing risk of epidural-intravenous misconnections. APSF Newsletter 2012;26:63-6.

30 Maddox RR, Williams CK. Clinical experience with capnography monitoring for PCA patients. APSF Newsletter 2012;26:47-50.

31 World Health Organization. Reporting and Learning Systems for Medication Errors: The Role of Pharmacovigilance Centres. Geneva, Switzerland: World Health Organization, 2014.

32 Lawton R, Gardner P, Green B, et al. An engineered solution to the maladministration of spinal injections. Qual Saf Health Care 2009;18:492-5.

33 McCarthy BC Jr, Tuiskula KA, Driscoll TP, et al. Medication errors resulting in harm: using chargemaster data to determine association with cost of hospitalization and length of stay. Am J Health Syst Pharm 2017;74:S102-7.

34 Thong WY, Pajel V, Khalil SN. Inadvertent administration of intravenous ropivacaine in a child. Paediatr Anaesth 2000;10:563-4.

35 Rapp HJ. Inadvertent i.v. bolus injection of ropivacaine in a 30-month-old child. Paediatr Anaesth 2002;12:87-8.

36 Dernedde M, Furlan D, Verbesselt R, et al. Grand mal convulsion after an accidental intravenous injection of ropivacaine. Anesth Analg 2004;98:521-3.

37 National Health Service. Patient Safety Alert 21: Safer practice with epidural injections and infusions. London, United Kingdom. Available: https://www.sps.nhs. uk/wp-content/uploads/2018/02/2007-NRLS-0396-Epidural-injectns-PSA-2007-0328-v1.pdf [Accessed 22 Sep 2020].

38 Cook TM, Counsell D, Wildsmith JAW. Major complications of central neuraxial block: report on the Third National Audit Project of the Royal College of Anaesthetists. Br J Anaesth 2009;102:179-90. 
39 Zhang Y, Dong YJ, Webster CS, et al. The frequency and nature of drug administration error during anaesthesia in a Chinese hospital. Acta Anaesthesio/ Scand 2013;57:158-64.

40 Health Quality \& Safety Commission New Zealand. Epidural medicines through intravenous lines. Available: https://www.hqsc.govt.nz/assets/Reportable-Events/ Publications/Open-book/OB-epidural-medications-intravenous.pdf [Accessed September 22, 2020].

41 Lonati D, Schicchi A, Paulin L, et al. Accidental epidural or intrathecal administration of thiocolchicoside can be lethal [abstract 130]. Clin Toxicol 2016;54:426-7.

42 Anesthesia Quality Institute. A case report from the anesthesia incident reporting system. ASA Monitor 2015;79:42-5.

43 Chowdhury P, Dabrowska D, Said H. "Eternal vigilance is the price of safety" : a case of inadvertent administration of oxytocin via epidural catheter. Eur J Anaesthesiol 2014;31:178.

44 Courreges P. Inadvertent epidural infusion of paracetamol in a child. Paediatr Anaesth 2005;15:1128-30.

45 Dehne MG. Inadvertent epidural infusion of paracetamol in an elderly patient. Central European Journal of Medicine 2011;6:595-7.

46 Furuya T, Suzuki T, Yokotsuka S, et al. Prolonged neuromuscular block after an accidental epidural injection of vecuronium. J Clin Anesth 2011;23:673.

47 Huang SY, Wang CC, Chang WK, et al. Intravenous propofol precipitates the hypotension induced by inadvertent epidural thiopental injection. Acta Anaesthesiol Taiwan 2006;44:239-42.

48 Kal JE, Vlassak EEW, Bulder ER, et al. Inadvertent epidural administration of insulin. Anaesthesia 2007;62:621-3.

49 Kaur J, Swami AC, Sharma A, et al. Inadvertent administration of potassium chloride in the epidural space: how to prevent the inevitable. J Anaesthesiol Clin Pharmacol 2019;35:137-8.

50 Kostopanagiotou G, Mylona M, Massoura L, et al. Accidental epidural injection of vecuronium. Anesth Analg 2000;91:1550-1.

51 Krataijan J, Laeni N. Accidental epidural injection of pancuronium. Anestha Analg 2005; 100:1546-7.

52 Kreutzträger M, Kopp MA, Liebscher T. Acute transient spinal paralysis and cardiac symptoms following an accidental epidural potassium infusion - a case report. BMC Anesthesiol 2017:17:135.

53 Kulka PJ, Stratesteffen I, Grunewald R, et al. [Inadvertent potassium chloride infusion in an epidural catheter]. Anaesthesist 1999;48:896-9.

54 Litz RJ, Kreinecker I, Hübler M, et al. Inadvertent infusion of a high dose of potassium chloride via a thoracic epidural catheter. Eur J Anaesthesio/ 2001;18:697-9.

55 Nishimoto K, Sakamoto S, Mikami M, et al. Accidental administration of the remifentanil formulation Ultiva ${ }^{\mathrm{TM}}$ into the epidural space and the complete time course of its consequences: a case report. JA Clin Rep 2016;2:19.

56 Olmez G, Yalinkaya A. Accidental epidural injection of ephedrine. Int J Obstet Anesth 2004;13:58-9.

57 Pourzitaki C, Tsaousi G, Logotheti H, et al. [Inadvertent injection of succinylcholine as an epidural test dose]. Rev Bras Anestesiol 2017;67:411-4.

58 Ross MJ, Wise A. Accidental epidural administration of Syntocinon. Int J Obstet Anesth 2012;21:203-4

59 Sidi A, Froelich MA. Inadvertent epidural injection of ephedrine in labor. J Clin Anesth 2004:16:74-6.

60 Sofianou A, Chatzieleftheriou A, Mavrommati P, et al. Accidental epidural administration of succinylcholine. Anesth Analg 2006;102:1139-40.

61 Tabuchi Y. [Accidental epidural administration of vecuronium]. Masui 2007;56:1429-32.

62 van der Steeg HJ, Beerens JL, van Akkeren JP, et al. Inadvertent infusion of potassium chloride via an epidural catheter. Acta Anaesthesiol Belg 2007;58:191-5.

63 Vassilakos D, Tsakiliotis S, Veroniki F, et al. Inadvertent epidural administration of cisatracurium. Eur J Anaesthesiol 2004;21:671-2.

64 Weigert A, Lawton G. Accidental injection of thiopental into the epidural space. Eur J Anaesthesiol 2000;17:69-70.

65 Yuksel Yildirim D, Gursoy F. Inadvertent administration of neostigmine-atropine mixture from epidural catheter. Turk J Anesthesiol Reanim 2014;42:273-6.

66 Lonati D, Schicchi A, Petrolini VM, et al. Peridural accidental administration of xenobiotics: an unpredictable outcome [abstract 180]. Clin Toxicol 2016;54:448-9.

67 Al Ferayan A, Russell NA, Al Wohaibi M, et al. Cerebrospinal fluid lavage in the treatment of inadvertent intrathecal vincristine injection. Childs Nerv Syst 1999;15:87-9.

68 Alcaraz A, Rey C, Concha A, et al. Intrathecal vincristine: fatal myeloencephalopathy despite cerebrospinal fluid perfusion. J Toxicol Clin Toxicol 2002;40:557-61.

69 Azarpira N, Pourjafar M, Rahmanian A. Inadvertent intrathecal injection of inappropriate ionic contrast media for myelography. Neurosurg Q 2013;23:275-7.

70 Balestrieri PJ, Hamza MS, Ting PH, et al. Inadvertent intrathecal injection of labetalol in a patient undergoing post-partum tubal ligation. Int J Obstet Anesth 2005; $14: 340-2$.

71 Barrett NA, Sundaraj SR. Inadvertent intrathecal injection of tramadol. Br J Anaesth 2003;91:918-20.

72 Brossner G, Engelhardt K, Beer R, et al. Accidental intrathecal infusion of cefotiam: clinical presentation and management. Eur J Clin Pharmacol 2004;60:373-5.
73 Chotsampancharoen T, Sripornsawan P, Wongchanchailert M. Two fatal cases of accidental intrathecal vincristine administration: learning from death events. Chemotherapy 2016;61:108-10.

74 Cottin J, Jean-Bart E, Sapori JM, et al. Accidental intrathecal administration of bleomycin: favourable outcome after cerebrospinal fluid exchange [abstract 163]. Clin Toxicol 2015;53:310.

75 D’Addario A, Galuppo J, Navari C, et al. Accidental intrathecal administration of vincristine. Am J Forensic Med Pathol 2010;31:83-4.

76 Dettmeyer R, Driever F, Becker A, et al. Fatal myeloencephalopathy due to accidental intrathecal vincristin administration: a report of two cases. Forensic Sci Int 2001:122:60-4.

77 Hennipman B, de Vries E, Bokkerink JP, et al. Intrathecal vincristine: 3 fatal cases and a review of the literature. J Pediatr Hematol Oncol 2009:31:816-9.

78 Iqbal Y, Abdullah MF, Tuner C, et al. Intrathecal vincristine: long-term survivor of potentially fatal chemotherapeutic error. Ann Saudi Med 2002;22:108-9.

79 Jordan B, Pasquier Y, Schnider A. Neurological improvement and rehabilitation potential following toxic myelopathy due to intrathecal injection of doxorubicin Spinal Cord 2004;42:371-3.

80 Karch AM. Vincristine: right drug, wrong route. Am J Nurs 2006;106:31-2.

81 Koch $\mathrm{R}, \mathrm{O}^{\prime}$ Connell C, Riddle $\mathrm{M}$, et al. Inadvertent administration of intrathecal tranexamic acid [abstract 20]. Clin Toxicol 2018;56:926-7.

82 Kwack EK, Kim DJ, Park TI, et al. Neural toxicity induced by accidental intratheca vincristine administration. J Korean Med Sci 1999;14:688-92.

83 Lonjaret L, Geeraerts T, Albucher J-F, et al. Early encephalic toxicity after inadvertent intrathecal injection of low osmolar contrast medium. Neuroradio/ $J$ 2012;25:222-4

84 Miranda HA, Khurana SR. Managing spinal cord injury caused by inadvertent intrathecal vincristine in a patient with T-cell acute lymphoblastic leukemia: a case report [abstract]. PM $R$ 2010;2:S180

85 Nelson ME, Tayag EC, Morell JA, et al. Intrathecal insult with iothalamate meglumine [abstract 64]. Clin Toxicol 2012;50:602

86 Olives T, Lintner C, Cole J. Physostigmine reversal of baclofen? Inadvertent administration of intrathecal physostigmine [abstract 94]. Clin Toxicol 2015;53:682-3

87 Pongudom S, Chinthammitr Y. Inadvertent intrathecal vincristine administration: report of a fatal case despite cerebrospinal fluid lavage and a review of the literature. J Med Assoc Thai 2011;94:S258-63.

88 Qweider M, Gilsbach JM, Rohde V. Inadvertent intrathecal vincristine administration: a neurosurgical emergency: case report. J Neurosurg Spine 2007:6:280-3

89 Saha AS, Islam MF, Bhattacharya S, et al. Clinical presentation of inadvertent intrathecal vincristine masquerading Guillain-Barre syndrome. Indian J Hematol Blood Transfus 2016;32:59-61.

90 Senbaga N, Davies EM. Inadvertent intrathecal administration of rifampicin. Br J Clin Pharmacol 2005;60:116.

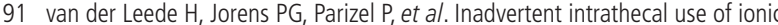
contrast agent. Eur Radiol 2002;12:S86-93.

92 Yeh H-M, Lau H-P, Lin P-L, et al. Convulsions and refractory ventricular fibrillation after intrathecal injection of a massive dose of tranexamic acid. Anesthesiology 2003:98:270-2

93 Singh S, Rejai S, Antongiorgi Z, et al. Misconnections in the critically ill: injection of high-dose gadolinium into an external ventricular drain. A A Case Rep 2016:6:121-3.

94 Naqvi A, Fadoo Z. Inadvertent intrathecal injection of PEG-asparaginase. J Pediatr Hematol Oncol 2010:32:416.

95 Stark AM, Barth H, Grabner J-P, et al. Accidental intrathecal mercury application. Eur Spine J 2004:13:241-3.

96 Noble DJ, Donaldson LJ. The quest to eliminate intrathecal vincristine errors: a 40 year journey. Qual Saf Health Care 2010;19:323-6.

97 Hew CM, Cyna AM, Simmons SW. Avoiding inadvertent epidural injection of drugs intended for non-epidural use. Anaesth Intensive Care 2003;31:44-9.

98 Wu AW, Lipshutz AK, Pronovost PJ. Effectiveness and efficiency of root cause analysis in medicine. JAMA 2008;299:685-7.

99 Labuschagne M, Robbetze W, Rozmiarek J, et al. Errors in drug administration by anaesthetists in public hospitals in the Free State. S Afr Med J 2011;101:324-7.

100 International Organization for Standardization. ISO 80369-1 2010: Small-bore connectors for liquids and gases in healthcare applications - Part 1: General requirements. Geneva, Switzerland. Available: https://www.iso.org/standard/45976. html [Accessed September 22, 2020].

101 International Organization for Standardization. ISO 80369-6:2016: Small bore connectors for liquids and gases in healthcare applications - Part 6: Connectors for neuraxial applications. Geneva, Switzerland. Available: https://www.iso.org/standard/ 50734.html [Accessed September 22, 2020].

102 Merry AF, Shipp DH, Lowinger JS. The contribution of labelling to safe medication administration in anaesthetic practice. Best Pract Res Clin Anaesthesiol 2011;25:145-59.

103 Ebbesen J, Buajordet I, Erikssen J, et al. Drug-related deaths in a department of internal medicine. Arch Intern Med 2001;161:2317-23. 